\title{
CONTRACEPÇÃO E ADOLESCÊNCIA(S): REVISÃO INTEGRATIVA
}

Catiele dos Santos

Adriane Roso

Flavi Ferreira Lisbôa Filho

Universidade Federal de Santa Maria
Recebido em: 27/07/2020

$1^{\text {a }}$ revisão em: 16/06/2021

Aceito em: 12/07/2021

\section{RESUMO}

Teve-se como objetivo sintetizar os resultados descritos em pesquisas acerca da temática da contracepção da população adolescente empreendidas no contexto brasileiro. Em específico, buscou-se identificar as informações sobre o uso de métodos contraceptivos e iniquidades de gênero. Trata-se de uma revisão integrativa de artigos científicos relativos à temática da contracepção de adolescentes, publicados no período de 2000 a 2019 e indexados no Portal de Periódicos da CAPES. A revisão contemplou 32 estudos. Identificou-se que o conhecimento dos métodos contraceptivos entre os(as) adolescentes é precário e - diálogo com a família, sobretudo com "figuras masculinas" configura-se enfraquecido. Evidenciou-se inequidade de gênero nas questões relacionadas ao aborto, gravidez e uso de métodos contraceptivos, bem como a utilização da expressão "gênero" no enquadre teórico do gênero binário, na maioria dos estudos analisados.

Palavras-chave: sexualidade; adolescente; educação; revisão. 


\section{CONTRACEPTION AND ADOLESCENCE(S): INTEGRATIVE REVIEW}

\section{ABSTRACT}

The objective was to synthesize the results obtained in research about the contraception in adolescent population undertaken in the Brazilian context. Specifically, we sought to identify information about the use of contraceptive methods and gender inequities. This is an integrative review of scientific articles on contraception in adolescents, published from 2000 to 2019 and indexed in the CAPES Journal Portal. The review contemplated 32 studies. It was identified that knowledge of contraceptive methods among adolescents is precarious and the dialogue with their families, especially with "male figures" is weakened. gender inequity was evidenced in issues related to abortion, pregnancy and the use of contraceptive methods, as well as the use of the expression "gender" in the theoretical framework of binary gender, in most of the analyzed studies.

Keywords: sexuality; teenager; education; review.

\section{CONTRACEPCIÓN Y ADOLESCENCIAS: REVISIÓN INTEGRADORA}

\section{RESUMEN}

El objetivo fue sintetizar los resultados descritos en las investigaciones sobre el tema de la anticoncepción en la población adolescente realizado en el contexto brasileño. En específico, trató de identificar información sobre el uso de métodos anticonceptivos y las inequidades de género. Esta es una revisión integradora de artículos científicos sobre el tema de la anticoncepción y la adolescencia, publicados entre 2000 y 2019 e indexados en el Portal CAPES. La revisión incluyó 32 estudios. Se identificó que el conocimiento de los métodos anticonceptivos entre los adolescentes es precario y el diálogo con la familia, especialmente con las "figuras masculinas" se presenta debilitado. La desigualdad de género fue evidente en cuestiones relacionadas con el aborto, el embarazo y el uso de métodos anticonceptivos, así como el uso de la expresión "género" en el marco teórico del género binario, en la mayoría de los estudios analizados.

Palabras clave: sexualidad; adolescente; educación; revisión. 


\section{INTRODUÇÃO}

O exercício da sexualidade na adolescência passa por desafios no contexto brasileiro atual, apesar das recentes e importantes conquistas relativas aos Direitos Sexuais e Reprodutivos (DSR). No cenário contemporâneo, vivencia-se um terreno instável no qual moralidades sexuais distintas parecem colidir e disputar lugares de poder nas estruturas do Estado. Desse modo, discursos normativos e religiosos de cunho conservador, acerca da equidade de gênero, do aborto, do casamento entre pessoas do mesmo sexo, da educação sexual nas escolas, têm unido setores em diversos países, em "defesa da família", da heterossexualidade e contra um pretenso desvirtuamento das crianças e dos adolescentes (Borges \& Borges, 2018; Leite, 2019).

Imbuída nesse cenário, a adolescência constitui um ponto estratégico para refletir sobre a importância do respeito aos DSR, principalmente acerca do acesso a informações de qualidade, no que tange à Saúde Sexual e Reprodutiva (SSR), enquanto dimensão de escolha por uma vida sexual prazerosa e segura, mediante o acesso a informações sobre a sexualidade, prevenção de IST/aids e à liberdade para decidirem se querem ter filhos, quando e com que frequência irão tê-los (Telo \& Witt, 2018). Afinal, no contexto social e político atual, a precariedade da vida, as inequidades de gênero, os silenciamentos, a negação dos DSR, culminam na exclusão dos saberes das(os) adolescentes, sendo estes reduzidos ao saber biomédico, o que lhes escamoteia a completude dos direitos sexuais e reprodutivos, bem como o direito de decidir sobre seus próprios corpos (Silva; Ferreira; Amaral-Bastos; Monteiro, \& Couto, 2020).

Os discursos e ações relativos à sexualidade/gênero e à população jovem se destacaram ao longo do período eleitoral para o cargo de presidente, em 2018, momento em que foram recuperados e disseminados materiais sobre a campanha Escola Sem Homofobia (2011) pela equipe do candidato conservador, Jair Messias Bolsonaro. A veiculação do material em questão foi empreendida de modo distorcido, o que provocou, para além do apelo público ao recolhimento do que foi erroneamente chamado de "Kit Gay", o incentivo à sua candidatura e o fortalecimento de sua figura política entre parte considerável da população brasileira. Ainda no mesmo ano, foi salientado por esse candidato, em uma live no Facebook, que "Quem ensina sexo é papai e mamãe, ponto final. Acabou. Não tem mais que discutir esse assunto. Agora, por isso precisamos de um bom ministro da educação [...] que realmente entenda que nós somos um país conservador" (Bolsonaro, 2018, online).

Na consolidação de práticas conservadoras, em março de 2019, Bolsonaro, então Presidente da República, afirmou "o Ministério da Saúde iria recolher e reformular a Caderneta de Saúde do Adolescente, publicação que traz ilustrações sobre como usar preservativos. [...] ele também sugeriu aos pais que cortassem essas páginas da publicação, [...]" (Schreiber, 2019). Em consonância com Bolsonaro, a chefe do Ministério da Mulher, da Família e dos Direitos Humanos, Damares Alves tem 
defendido que nas escolas brasileiras, os jovens (principalmente as meninas) devem ser orientados a não fazer sexo, ou seja, a ministra defende a abstinência sexual (Desideri \& Kadanus, 2019).

Ações e discursos como estes serviram de alerta para a possível redução nos investimentos em políticas de educação sexual progressistas e pouco reconhecimento da função ocupada pela escola e educadores nas ações relativas à tal temática, diante da omissão e/ou dificuldades encontradas por muitos pais em tratar do assunto. Diante deste panorama, Leite (2019) argumenta que as conquistas históricas no campo social, educacional e político, no que tange aos direitos sexuais dos adolescentes, tornam-se alvos de questionamento e de descumprimento. Tendo como base um viés biológico e reducionista do binarismo de gênero, articulado a uma hierarquização das orientações sexuais, o ideário da "ideologia de gênero" tem sido utilizado para defender a manutenção de uma ordem hierárquica e desigual entre as pessoas em nome da defesa das crianças e dos jovens (Leite, 2019).

Embora no campo dos direitos sexuais e reprodutivos da adolescência esforços têm sido alcançados gradativamente, acompanhados pela sociedade civil através do controle social, ampliados e aprofundados com o auxílio da ciência, das mudanças culturais e de novas conjunturas econômicas e sociais, no Brasil o avanço ainda engatinha (Moraes \& Vitalli, 2014). Além disso, em relação à saúde sexual e reprodutiva dos(as) adolescentes, observa-se uma ênfase nos aspectos biológicos da reprodução, com foco na prevenção de IST, HIV/aids, "gravidez na adolescência", iniciação sexual "precoce", bem como acerca do uso correto de métodos contraceptivos (Campos; Paiva; Mourthé; Ferreira, \& Fonseca, 2017; Pinheiro; Silva, \& Tourinho, 2017; Vieira \& Matsukura, 2017).

Esse viés também se faz presente no campo acadêmico, no qual a contracepção tem sido abordada por diferentes áreas, com destaque para as ciências humanas e da saúde. De forma majoritária, são atribuídos à contracepção sentidos relativos ao uso correto de métodos contraceptivos (Mendonça \& Araújo, 2009), à iniciação sexual precoce (Moraes et al., 2019), à gravidez na adolescência (Campos et al., 2017; Russo \& Arreguy, 2015; Dias; Alves; Viana; Santos, \& Silva, 2015) e às Infecções e Doenças Sexualmente Transmissíveis - IST/DST (Queiroz, Alcântara, Brasil, \& Silva, 2016). No entanto, permanecem lacunas na literatura sobre a sexualidade de adolescentes, em especial entre aqueles que residem em áreas de fronteira, como é o caso dos limites entre Brasil, Argentina e Paraguai (Priotto, Fuhr, Gomes, \& Barbosa, 2018). Portanto, a problemática da contracepção figura como tema de relevância, à medida que sua expressão tem sido limitada aos aspectos biológicos, fisiológicos e biomédicos, inclusive no contexto das pesquisas acadêmicas.

Com base em uma revisão integrativa, objetiva-se sintetizar os resultados descritos em pesquisas que tratam sobre contracepção e adolescência no contexto brasileiro, com atenção especial no que diz respeito aos métodos contraceptivos e 
às iniquidades de gênero. A questão que norteia este estudo é: (1) Quais são as evidências apresentadas em estudos empíricos realizados com adolescentes no contexto brasileiro, no que tange à contracepção e aos métodos contraceptivos, incluída a prática do aborto?

A partir da perspectiva de direitos sexuais e reprodutivos (Corrêa, 1999; Moraes \& Vitalli, 2014; Reis \& Eggert, 2017) e de uma perspectiva crítica da adolescência (Ozella \& Aguiar, 2008; Berni \& Roso, 2014; Campos et al., 2017), entende-se que, no que tange ao estudo da reprodução nas adolescências, sobretudo em relação à temática da contracepção, esta se apresenta entrelaçada com as questões das masculinidades e feminilidades. Diante disso, entre os resultados esperados, almeja-se provocar os estudiosos da adolescência e os profissionais da saúde para que se engajem em perspectivas de gênero, para além do binarismo.

\section{MÉTODO}

Trata-se de uma revisão integrativa de artigos científicos indexados no Portal de Periódicos da CAPES e oriundos de pesquisas empíricas realizadas junto a adolescentes no que tange à temática da contracepção. Enquanto método, a revisão integrativa de literatura objetiva sintetizar resultados obtidos em pesquisas sobre um tema ou questão, de maneira sistemática, ordenada e abrangente (Ercole; Melo, \& Alcoforado, 2014). Por meio da adoção dela, o(a) pesquisador(a) pode elaborar uma revisão integrativa com diferentes intuitos, desde a definição de conceitos até a análise metodológica dos estudos encontrados.

O estudo compõe uma pesquisa de mestrado intitulada "Tecnologias da Informação e Comunicação e identidades: diálogos com adolescentes em uma escola", aprovada pelo comitê de ética sob o CAAE: 37234120.3.0000.5346. A pesquisa vincula-se a um projeto maior (guarda-chuva) que tem como objetivo discutir as políticas de reprodução e, em específico, identificar como certas estratégias ideológicas se difundiram na sociedade, tais como a medicalização do corpo humano e os mitos legitimadores relacionados à política de reprodução.

Essa revisão tem como finalidade apresentar as contribuições dos estudos brasileiros relativos à temática da contracepção, a partir de uma análise crítica das informações trazidas pelos mesmos. Desse modo, a operacionalização do estudo contou com as seguintes etapas: definição da questão de pesquisa, seleção de critérios para a pesquisa dos artigos, análise, interpretação e discussão dos resultados.

A construção das informações empíricas foi empreendida junto à base de dados Portal Capes, durante o mês de janeiro de 2020. Foram utilizados os descritores "métodos contraceptivos", "anticoncepcionais", "adolescência" e "contracepção", operados pelo bolean AND. Posteriormente, foram elencados os idiomas Inglês, Português e Espanhol e o tipo de material "somente artigo". Selecionou-se o período de publicação correspondente ao intervalo 2000 a 2019, etapa na qual 
obteve-se o montante de 167 artigos. Após, foi selecionada a opção "periódico revisado por pares", etapa que resultou no total de 135 resultados.

Concluída esta etapa, houve a aplicação dos critérios de inclusão: a) trabalhos disponibilizados na íntegra, b) estudos correspondentes à área das ciências humanas e ciências da saúde, c)" pesquisas realizadas em estados, municípios, cidades e regiões brasileiras e, em relação ao tipo de material, foi utilizado o critério d) apenas artigos. A partir de tais critérios, realizou-se a exclusão de editoriais, teses e dissertações, resenhas de livros, livros e capítulos de livro, anais de eventos, estudos duplicados, pesquisas internacionais e estudos que não versavam especificamente a respeito da temática da contracepção nas adolescências.

Nesta etapa, obteve-se o total de 55 artigos, que foram submetidos aos critérios de inclusão, dos quais foram excluídos 09 estudos, sendo obtidos 46 estudos, que foram analisados em sua forma completa. Destes, 14 estudos não atenderam ao critério de inclusão "estudo empírico que contasse com a participação de adolescentes como participantes da pesquisa". 32 artigos constituíram o corpus de análise, conforme o fluxograma (Figura 1).

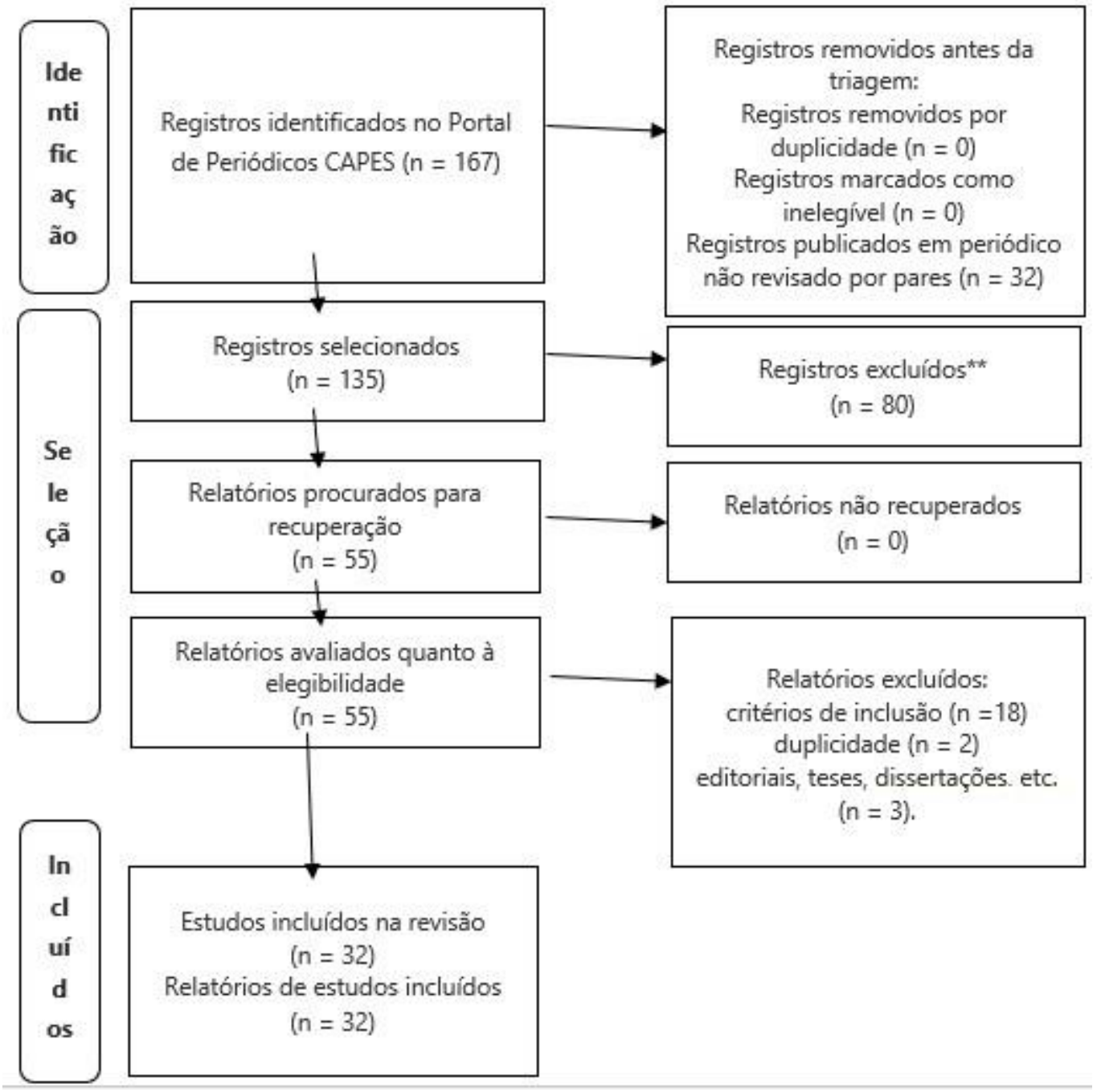

Figura 1.

Fluxograma de identificação e seleção dos estudos. 


\section{RESULTADOS E DISCUSSÃO}

Tabela 1.

\section{Síntese dos estudos}

\begin{tabular}{|c|c|c|c|}
\hline Autoria & Objetivos & $\begin{array}{c}\text { Técnica de coleta } \\
\text { de dados }\end{array}$ & Participantes \\
\hline $\begin{array}{l}\text { Alves e } \\
\text { Brandão } \\
(2009)\end{array}$ & $\begin{array}{l}\text { Discutir situações de } \\
\text { vulnerabilidade no uso de } \\
\text { métodos contraceptivos nas } \\
\text { relações afetivo-sexuais na } \\
\text { adolescência e juventude. }\end{array}$ & $\begin{array}{c}\text { Entrevista } \\
\text { semiestruturada }\end{array}$ & $\begin{array}{l}\text { Adolescentes (18 e } 24 \\
\text { anos) do município do } \\
\text { Rio de Janeiro. }\end{array}$ \\
\hline $\begin{array}{c}\text { Baptista, } \\
\text { Maciel, } \\
\text { Caldeira, } \\
\text { Tupinambás e } \\
\text { Greco (2012) }\end{array}$ & $\begin{array}{l}\text { Determinar e comparar as } \\
\text { prevalências de fatores de } \\
\text { risco individuais para } \\
\text { DST/HIV/aids entre } \\
\text { adolescentes de Montes } \\
\text { Claros, Brasil. }\end{array}$ & Questionário & $\begin{array}{l}775 \text { estudantes (idade } \\
\text { maior ou igual a } 13 \\
\text { anos), em } 12 \text { escolas } \\
\text { públicas. }\end{array}$ \\
\hline $\begin{array}{l}\text { Belo e Silva } \\
\text { (2004) }\end{array}$ & $\begin{array}{l}\text { Estudar o conhecimento, a } \\
\text { atitude e a prática em relação } \\
\text { ao uso prévio de métodos } \\
\text { anticoncepcionais em } \\
\text { adolescentes gestantes. }\end{array}$ & Questionário & $\begin{array}{c}156 \text { adolescentes } \\
\text { grávidas com idade } \\
\text { menor ou igual a } 19 \\
\text { anos. }\end{array}$ \\
\hline $\begin{array}{l}\text { Bié, Diógenes } \\
\text { e Moura } \\
(2006)\end{array}$ & $\begin{array}{l}\text { Identificar o conhecimento } \\
\text { de adolescentes sobre o } \\
\text { planejamento familiar e } \\
\text { métodos contraceptivos, } \\
\text { descrever as fontes de } \\
\text { informações sobre o assunto } \\
\text { e verificar os benefícios da } \\
\text { educação sexual com } \\
\text { adolescentes }\end{array}$ & $\begin{array}{c}\text { Entrevista } \\
\text { semiestruturada e } \\
\text { entrevista grupal. }\end{array}$ & $\begin{array}{c}10 \text { adolescentes (14 e } \\
19 \text { anos). }\end{array}$ \\
\hline $\begin{array}{c}\text { Borovac- } \\
\text { Pinheiro, Jesus } \\
\text { e Surita (2019) }\end{array}$ & $\begin{array}{c}\text { Avaliar o uso de } \\
\text { anticoncepcionais por mães } \\
\text { adolescentes com crescente } \\
\text { escolha para métodos de } \\
\text { contracepção reversível de } \\
\text { longa ação na consulta pós- } \\
\text { parto. }\end{array}$ & Grupos de discussão & 129 adolescentes. \\
\hline $\begin{array}{c}\text { Brêtas e Silva } \\
\text { (2002) }\end{array}$ & $\begin{array}{l}\text { Identificar qual o interesse } \\
\text { dos sujeitos sobre o corpo e } \\
\text { sexualidade; contribuir com } \\
\text { os dados para elaboração de } \\
\text { um Programa de Orientação } \\
\text { Sexual. }\end{array}$ & $\begin{array}{c}\text { Questionário } \\
\text { semiestruturado }\end{array}$ & $\begin{array}{l}493 \text { escolares (7 a } 18 \\
\text { anos), de ambos os } \\
\text { sexos, frequentadores } \\
\text { de três Centros da } \\
\text { Juventude e um Centro } \\
\text { de Formação } \\
\text { Profissional. }\end{array}$ \\
\hline $\begin{array}{c}\text { Camargo e } \\
\text { Ferrari (2009) }\end{array}$ & $\begin{array}{l}\text { Analisar o conhecimento dos } \\
\text { adolescentes sobre } \\
\text { sexualidade, métodos } \\
\text { contraceptivos, gravidez, DST } \\
\text { e aids, antes e após oficinas } \\
\text { de prevenção. }\end{array}$ & $\begin{array}{c}\text { Questionário } \\
\text { semiestruturado }\end{array}$ & $\begin{array}{l}117 \text { adolescentes, de } \\
\text { três turmas da } 8^{a} \text { série } \\
\text { do ensino fundamental } \\
\text { de uma escola pública. }\end{array}$ \\
\hline $\begin{array}{c}\text { Canavez, } \\
\text { Soares, Silva e } \\
\text { Chaves (2010) }\end{array}$ & $\begin{array}{l}\text { Identificar o conhecimento } \\
\text { dos adolescentes acerca da } \\
\text { gravidez quando inicia sua } \\
\text { vida sexual, com vistas à }\end{array}$ & $\begin{array}{c}\text { Formulário } \\
\text { semiestruturado }\end{array}$ & $\begin{array}{l}40 \text { alunos (13-17 anos) } \\
\text { do } 9^{\circ} \text { ano do Ensino } \\
\text { Fundamental, de uma } \\
\text { instituição de ensino }\end{array}$ \\
\hline
\end{tabular}




\begin{tabular}{|c|c|c|c|}
\hline & $\begin{array}{l}\text { prevenção da gravidez } \\
\text { precoce. }\end{array}$ & & $\begin{array}{l}\text { da rede pública, de } \\
\text { Volta Redonda - RJ. }\end{array}$ \\
\hline $\begin{array}{l}\text { Cerqueira- } \\
\text { Santos, } \\
\text { Paludo, Schiró } \\
\text { e Koller (2010) }\end{array}$ & $\begin{array}{l}\text { Identificar as diferenças } \\
\text { existentes entre um grupo de } \\
\text { adolescentes que viveu a } \\
\text { experiência de gravidez } \\
\text { durante a adolescência. }\end{array}$ & $\begin{array}{c}\text { Questionário } \\
\text { semiestruturado }\end{array}$ & $\begin{array}{l}1015 \text { jovens (14-24 } \\
\text { anos) de ambos os } \\
\text { sexos. }\end{array}$ \\
\hline $\begin{array}{c}\text { Correia, } \\
\text { Cavalcanti, } \\
\text { Egito e Maia } \\
\quad(2011)\end{array}$ & $\begin{array}{c}\text { Investigar as razões que } \\
\text { levaram adolescentes, com } \\
\text { idades entre } 12 \text { aos } 19 \text { anos, } \\
\text { do sexo feminino, a } \\
\text { provocarem o aborto, } \\
\text { relacionando com idade e } \\
\text { tipo de escola que } \\
\text { frequentavam. }\end{array}$ & $\begin{array}{c}\text { Questionário } \\
\text { semiestruturado }\end{array}$ & $\begin{array}{c}2.592 \text { adolescentes do } \\
\text { sexo feminino (12 a } 19 \\
\text { anos). }\end{array}$ \\
\hline $\begin{array}{l}\text { Costa. Guerra } \\
\text { e Araújo } \\
\text { (2016) }\end{array}$ & $\begin{array}{c}\text { Investigar comunicação, } \\
\text { conhecimentos, atitudes e } \\
\text { comportamento sexual dos } \\
\text { adolescentes. }\end{array}$ & Entrevistas & $\begin{array}{c}570 \text { adolescentes (11 a } \\
19 \text { anos) de uma escola } \\
\text { pública. }\end{array}$ \\
\hline $\begin{array}{c}\text { Farias e Moré } \\
(2012)\end{array}$ & $\begin{array}{l}\text { Identificar as repercussões } \\
\text { ocorridas na vida de } \\
\text { adolescentes que } \\
\text { engravidaram entre } 12 \text { e } 14 \\
\text { anos, em contexto de } \\
\text { vulnerabilidade social. }\end{array}$ & $\begin{array}{c}\text { Entrevistas } \\
\text { semiestruturadas e } \\
\text { aplicação de mapas } \\
\text { de redes. }\end{array}$ & $\begin{array}{c}10 \text { adolescentes do } \\
\text { sexo feminino (12 a } 14 \\
\text { anos). }\end{array}$ \\
\hline $\begin{array}{l}\text { Ferrari e Peres } \\
\quad(2020)\end{array}$ & $\begin{array}{l}\text { Examinar a questão do } \\
\text { aborto ocorrido na } \\
\text { adolescência e as estratégias } \\
\text { usadas pelas adolescentes } \\
\text { para concretizá-lo em } \\
\text { contexto ilegal. }\end{array}$ & $\begin{array}{c}\text { Entrevista } \\
\text { semiestruturada }\end{array}$ & $\begin{array}{c}10 \text { jovens (15 a } 17 \\
\text { anos) com experiência } \\
\text { de aborto ilegal } \\
\text { praticado entre } 12 \text { e } 17 \\
\text { anos, moradoras de } \\
\text { uma favela do Rio de } \\
\text { Janeiro. }\end{array}$ \\
\hline $\begin{array}{c}\text { Ferrari, Peres } \\
\text { e Nascimento } \\
\quad(2018)\end{array}$ & $\begin{array}{c}\text { Abordar o tema da iniciação } \\
\text { sexual na adolescência, com } \\
\text { foco nas narrativas de dez } \\
\text { jovens com experiência de } \\
\text { aborto induzido, moradoras } \\
\text { de uma favela do Rio de } \\
\text { Janeiro }\end{array}$ & $\begin{array}{c}\text { Entrevista } \\
\text { semiestruturada }\end{array}$ & $\begin{array}{l}10 \text { jovens moradoras } \\
\text { de uma favela, com } \\
\text { experiência de aborto } \\
\text { induzido. }\end{array}$ \\
\hline $\begin{array}{c}\text { Ferreira, } \\
\text { Gonçalves e } \\
\text { Jamas (2010) }\end{array}$ & $\begin{array}{c}\text { Descrever o comportamento } \\
\text { das mulheres em relação à } \\
\text { planificação familiar e } \\
\text { analisar se tal } \\
\text { comportamento tem } \\
\text { influência cultural. }\end{array}$ & $\begin{array}{c}\text { Entrevista } \\
\text { semiestruturada }\end{array}$ & $\begin{array}{l}17 \text { mulheres (14-35 } \\
\text { anos) do município de } \\
\text { Ilha Comprida, São } \\
\text { Paulo, Brasil. }\end{array}$ \\
\hline $\begin{array}{c}\text { Fonseca, } \\
\text { Gomes e } \\
\text { Barreto (2015) }\end{array}$ & $\begin{array}{l}\text { Avaliar o perfil das usuárias } \\
\text { do Programa Assistência } \\
\text { Integral à Saúde da Mulher } \\
\text { (PAISM) no município de São } \\
\text { José do Calçado - ES }\end{array}$ & $\begin{array}{l}\text { Questionário } \\
\text { semiestruturado }\end{array}$ & $\begin{array}{l}30 \text { usuárias (12-60 } \\
\text { anos) do Programa de } \\
\text { Assistência Integral à } \\
\text { Saúde da Mulher } \\
\text { (PAISM). }\end{array}$ \\
\hline $\begin{array}{l}\text { Gubert e } \\
\text { Madureira } \\
(2008)\end{array}$ & $\begin{array}{l}\text { Investigar a iniciação sexual } \\
\text { de adolescentes do sexo } \\
\text { masculino em Concórdia, } \\
\text { Santa Catarina/SC. }\end{array}$ & $\begin{array}{c}\text { Entrevista } \\
\text { semiestruturada }\end{array}$ & $\begin{array}{l}340 \text { adolescentes do } \\
\text { sexo masculino (14 a } \\
19 \text { anos), de seis } \\
\text { instituições de ensino } \\
\text { do município de } \\
\text { Concórdia, SC. }\end{array}$ \\
\hline
\end{tabular}




\begin{tabular}{|c|c|c|c|}
\hline $\begin{array}{l}\text { Maranhão, } \\
\text { Gomes, } \\
\text { Oliveira e } \\
\text { Neto (2017) }\end{array}$ & $\begin{array}{l}\text { Analisar a repercussão da } \\
\text { iniciação sexual de jovens } \\
\text { com antecedentes } \\
\text { obstétricos no número de } \\
\text { gestações e de parceiros, em } \\
\text { Teresina (PI). }\end{array}$ & $\begin{array}{c}\text { Entrevista } \\
\text { semiestruturada }\end{array}$ & $\begin{array}{c}464 \text { jovens que } \\
\text { finalizaram uma } \\
\text { gravidez quando } \\
\text { tinham idade de } 15 \text { a } \\
19 \text { anos. }\end{array}$ \\
\hline $\begin{array}{l}\text { Mendes, } \\
\text { Moreira, } \\
\text { Martins, } \\
\text { Souza e } \\
\text { Matos (2011) }\end{array}$ & $\begin{array}{l}\text { Descrever e analisar os } \\
\text { saberes e atitudes dos } \\
\text { adolescentes sobre a } \\
\text { contracepção. }\end{array}$ & $\begin{array}{l}\text { Questionário } \\
\text { estruturado }\end{array}$ & $\begin{array}{c}499 \text { adolescentes de } \\
\text { cinco escolas estaduais } \\
\text { de Cuiabá, Mato } \\
\text { Grosso. }\end{array}$ \\
\hline $\begin{array}{c}\text { Moreira, } \\
\text { Dumith e } \\
\text { Paludo (2018) }\end{array}$ & $\begin{array}{l}\text { Medir a prevalência do uso } \\
\text { de preservativo na última } \\
\text { relação sexual entre } \\
\text { universitários e os fatores } \\
\text { associados. }\end{array}$ & $\begin{array}{l}\text { Questionário } \\
\text { autoaplicável }\end{array}$ & $\begin{array}{l}1215 \text { universitários, } \\
\text { com idade igual ou } \\
\text { superior a } 18 \text { anos. }\end{array}$ \\
\hline $\begin{array}{c}\text { Moreira e } \\
\text { Sarriera (2006) }\end{array}$ & $\begin{array}{l}\text { Avaliar os preditores de } \\
\text { saúde e bem-estar de } \\
\text { adolescentes gestantes. }\end{array}$ & $\begin{array}{c}\text { Questionário para } \\
\text { dados } \\
\text { biodemográficos e } \\
\text { Questionário Geral } \\
\text { de Saúde de } \\
\text { Golberg. }\end{array}$ & $\begin{array}{c}100 \text { adolescentes } \\
\text { gestantes (12-19) anos, } \\
\text { em hospitais da rede } \\
\text { pública de Porto } \\
\text { Alegre/RS. }\end{array}$ \\
\hline $\begin{array}{c}\text { Moreira, } \\
\text { Rocha, Puntel } \\
\text { e Folmer } \\
\text { (2011) }\end{array}$ & $\begin{array}{l}\text { Discutir as principais dúvidas } \\
\text { e curiosidades emergentes } \\
\text { de uma pesquisa sobre } \\
\text { dúvidas e curiosidades dos } \\
\text { adolescentes acerca da } \\
\text { sexualidade, discutindo o } \\
\text { papel desempenhado pelos } \\
\text { adultos de referência. }\end{array}$ & $\begin{array}{c}\text { Questionário. } \\
\text { semiestruturado e } \\
\text { grupos de discussão }\end{array}$ & $\begin{array}{c}42 \text { alunos que } \\
\text { estudavam em duas } \\
\text { escolas da rede pública } \\
\text { de ensino fundamental } \\
\text { e médio, em } \\
\text { Uruguaiana/Rio Grande } \\
\text { do Sul (Brasil). }\end{array}$ \\
\hline $\begin{array}{c}\text { Moura, } \\
\text { Gomes, } \\
\text { Rodrigues e } \\
\text { Oliveira (2011) }\end{array}$ & $\begin{array}{c}\text { Descrever as fontes de } \\
\text { informação sobre } \\
\text { sexualidade e contracepção } \\
\text { utilizadas por adolescentes } \\
\text { que vivenciaram uma } \\
\text { gravidez. }\end{array}$ & $\begin{array}{c}\text { Formulário } \\
\text { semiestruturado e } \\
\text { entrevista } \\
\text { semiestruturada. }\end{array}$ & $\begin{array}{l}285 \text { adolescentes do } \\
\text { sexo feminino, em } \\
\text { quatro maternidades } \\
\text { de Teresina-PI. }\end{array}$ \\
\hline $\begin{array}{l}\text { Neiva-Silva et } \\
\text { al. (2018) }\end{array}$ & $\begin{array}{l}\text { Identificar a prevalência de } \\
\text { experiência de gravidez e } \\
\text { aborto e os fatores } \\
\text { associados em crianças, } \\
\text { adolescentes e jovens em } \\
\text { situação de rua, das cidades } \\
\text { de Porto Alegre e Rio } \\
\text { Grande, RS, Brasil. }\end{array}$ & $\begin{array}{l}\text { Questionário } \\
\text { estruturado }\end{array}$ & $\begin{array}{c}307 \text { pessoas (10 a } 21 \\
\text { anos). }\end{array}$ \\
\hline $\begin{array}{l}\text { Patias e Dias } \\
\quad(2014)\end{array}$ & $\begin{array}{l}\text { Comparar a idade da } \\
\text { primeira relação sexual, a } \\
\text { informação sobre métodos } \\
\text { contraceptivos, além de seu } \\
\text { uso com a ocorrência da } \\
\text { gestação na adolescência. }\end{array}$ & $\begin{array}{c}\text { Questionário } \\
\text { semiestruturado }\end{array}$ & $\begin{array}{l}100 \text { adolescentes (13 a } \\
19 \text { anos) que } \\
\text { frequentavam } \\
\text { instituições públicas da } \\
\text { cidade de Santa Maria, } \\
\text { interior do RS. }\end{array}$ \\
\hline $\begin{array}{l}\text { Pelloso, } \\
\text { Carvalho e } \\
\text { Hiragashl } \\
\text { (2008) }\end{array}$ & $\begin{array}{l}\text { Compreender a vivência da } \\
\text { sexualidade de jovens de } \\
\text { ambos os sexos, com ênfase } \\
\text { nas questões de gênero. }\end{array}$ & $\begin{array}{c}\text { Questionário } \\
\text { semiestruturado }\end{array}$ & $\begin{array}{l}80 \text { adolescentes (12-19 } \\
\text { anos) de uma escola } \\
\text { estadual localizada em } \\
\text { um município de } \\
\text { pequeno porte do } \\
\text { Noroeste do Paraná. }\end{array}$ \\
\hline $\begin{array}{c}\text { Pirotta e } \\
\text { Schorb (2002) }\end{array}$ & $\begin{array}{l}\text { Identificar as intenções } \\
\text { reprodutivas e caracterizar as }\end{array}$ & $\begin{array}{l}\text { Entrevistas em } \\
\text { profundidade e }\end{array}$ & $\begin{array}{l}952 \text { estudantes de } \\
\text { graduação, com idade }\end{array}$ \\
\hline
\end{tabular}




\begin{tabular}{|c|c|c|c|}
\hline & $\begin{array}{c}\text { práticas de regulação da } \\
\text { fecundidade, abarcando a } \\
\text { contracepção e o aborto, } \\
\text { entre um grupo de } \\
\text { adolescentes e jovens de alta } \\
\text { escolaridade. }\end{array}$ & $\begin{array}{l}\text { Questionário } \\
\text { autoaplicável. }\end{array}$ & $\begin{array}{l}\text { de até } 24 \text { anos, de uma } \\
\text { universidade pública } \\
\text { estadual localizada na } \\
\text { cidade de São Paulo. }\end{array}$ \\
\hline $\begin{array}{c}\text { Queiroz, } \\
\text { Alcântara, } \\
\text { Brasil e Silva } \\
\text { (2016) }\end{array}$ & $\begin{array}{l}\text { Descrever a participação de } \\
\text { adolescentes em ações } \\
\text { educativas sobre saúde } \\
\text { sexual e contracepção. }\end{array}$ & $\begin{array}{l}\text { Rodas de conversas } \\
\text { e oficinas educativas. }\end{array}$ & $\begin{array}{l}30 \text { adolescentes do } 8^{\circ} \\
\text { e } 9^{\circ} \text { anos da Escola do } \\
\text { Ensino Fundamental, } \\
\text { em Fortaleza, Ceará. }\end{array}$ \\
\hline $\begin{array}{l}\text { Spindola, } \\
\text { Siqueira e } \\
\text { Cavalcanti } \\
\text { (2012) }\end{array}$ & $\begin{array}{l}\text { Conhecer a percepção das } \\
\text { gestantes adolescentes sobre } \\
\text { emprego dos métodos } \\
\text { contraceptivos e discutir a } \\
\text { vivência das jovens } \\
\text { relacionada à contracepção e } \\
\text { práticas sexuais. }\end{array}$ & $\begin{array}{c}\text { Entrevista } \\
\text { semiestruturada }\end{array}$ & $\begin{array}{c}17 \text { gestantes } \\
\text { adolescentes, com } \\
\text { idade inferior a } 19 \\
\text { anos. }\end{array}$ \\
\hline $\begin{array}{l}\text { Spinola, Béria } \\
\text { e Schermann } \\
(2017)\end{array}$ & $\begin{array}{c}\text { Analisar os fatores } \\
\text { associados à iniciação sexual. }\end{array}$ & $\begin{array}{c}\text { Entrevista } \\
\text { semiestruturada }\end{array}$ & $\begin{array}{l}427 \text { mães (14 a } 16 \\
\text { anos) de Porto } \\
\text { Alegre/RS/Brasil. }\end{array}$ \\
\hline $\begin{array}{l}\text { Schor et al. } \\
\text { (2007) }\end{array}$ & $\begin{array}{l}\text { Caracterizar o cotidiano e } \\
\text { vida sexual de } 108 \\
\text { adolescentes residentes em } \\
\text { Serra Pelada, município de } \\
\text { Curionópolis, PA. }\end{array}$ & $\begin{array}{l}\text { Questionário } \\
\text { semiestruturado }\end{array}$ & $\begin{array}{c}08 \text { adolescentes (11 a } \\
15 \text { anos), residentes em } \\
\text { Serra Pelada, município } \\
\text { de Curionópolis, } \\
\text { Estado do Pará. }\end{array}$ \\
\hline $\begin{array}{c}\text { Tavares, } \\
\text { Paganotto, } \\
\text { Frare, } \\
\text { Carvalho e } \\
\text { Pelloso (2012) }\end{array}$ & $\begin{array}{l}\text { Traçar o perfil de puérperas } \\
\text { adolescentes atendidas em } \\
\text { um Hospital Ensino do Sul do } \\
\text { país }\end{array}$ & $\begin{array}{c}\text { Entrevista } \\
\text { semiestruturada }\end{array}$ & $\begin{array}{c}225 \text { puérperas } \\
\text { adolescentes (13-19 } \\
\text { anos) atendidas no } \\
\text { Hospital Universitário } \\
\text { do Oeste do Paraná. }\end{array}$ \\
\hline
\end{tabular}

Com o objetivo de sintetizar os resultados descritos em pesquisas que tratam sobre contracepção e adolescência no contexto brasileiro, a seguir são descritas algumas características sociodemográficas identificadas nos estudos analisados (situação econômica, contexto escolar, religião), no que se refere às práticas contraceptivas de adolescentes. A seguir, dividiu-se a apresentação dos resultados em quatro eixos temáticos: (a) Contracepção e métodos contraceptivos: evidências dos estudos, (b) Produção de conhecimentos e comunicação em saúde, (c) Iniquidades de gênero: (in)diferenças em cena e (d) Limitações e recomendações nos estudos analisados. Os eixos temáticos foram organizados de acordo com as informações obtidas a partir dos estudos incluídos na revisão.

\section{CARACTERÍSTICAS SOCIODEMOGRÁFICAS}

\section{SITUAÇÃO ECONÔMICA}

Em relação à gravidez, o entendimento de Cerqueira-Santos et al. (2010) é de que a condição de pobreza potencializa a exposição aos riscos que, de alguma forma, ameaçam o desenvolvimento saudável, embora focalizar a explicação da gravidez na adolescência exclusivamente nessa questão impede um olhar ecológico para esse fenômeno. Para os autores, a pertença a um nível socioeconômico baixo pode 
traduzir um micro e mesossistema mais carenciado ao nível das informações sobre sexualidade, cuidados de saúde e importância de contracepção, assim como no acesso aos serviços de saúde e, por esse motivo, um contexto de maior risco.

Belo e Silva (2004) salientam que as adolescentes com maior nível socioeconômico apresentaram conhecimento significativamente maior sobre os métodos anticoncepcionais, o que parece indicar que as classes consideradas mais privilegiadas teriam maior acesso e contato com os meios de informação mais eficientes. Diferentemente, Tavares et al. (2012) argumentam que o fato de algumas garotas desconhecerem o valor da renda familiar demonstra que a condição de gravidez não foi conscientemente planejada em suas vidas.

Costa et al. (2016) corroboram dados existentes na literatura, ao apontarem que adolescentes provenientes de famílias de baixa renda, com nível fundamental de escolaridade encontram-se entre os mais vulneráveis à gravidez na adolescência. No entendimento desses autores, esses adolescentes têm iniciado suas atividades sexuais sem orientação contraceptiva e com conhecimentos e atitudes que limitam o uso de métodos contraceptivos. Logo, estão expostos à gravidez não planejada, à medida que a maioria dos adolescentes que já haviam iniciado suas práticas sexuais nunca havia usado qualquer método contraceptivo.

Moura et al. (2011) também relacionaram a maternidade na adolescência com baixa escolaridade e ausência de trabalho remunerado, características que apontam para a relação entre condição socioeconômica desfavorável, educação precária e falta de perspectiva de vida, fatores que contribuem para a perpetuação do ciclo de pobreza.

A renda da família também se apresenta como um dos determinantes para a utilização dos serviços de saúde pública. No estudo de Moura e Gomes (2014), a renda apresentou relevante associação com o uso dos serviços públicos de planejamento familiar, os quais são utilizados principalmente por pessoas de menor renda e geralmente sem acesso a planos de saúde e serviços médicos privados. Observou-se, também, que as jovens com renda familiar maior que três salários-mínimos se apresentaram 20\% mais propensas a não serem usuárias dos serviços de planejamento familiar, quando comparadas às que possuíam até um salário-mínimo. Igualmente, evidenciou-se que a experiência de gravidez anterior aumentou em 1,6 vezes as chances de uso do serviço.

A dependência financeira das adolescentes gestantes para com a família e a baixa renda desta reforça a probabilidade de deixarem de estudar, bem como contribui para a piora da qualificação profissional como consequência, o que pode desencadear, ainda, à tendência de ter proles numerosas e contribuir para a criação e perpetuação de um ciclo de manutenção da pobreza (Tavares et al., 2012). De forma semelhante, Correia et al. (2011) reiteram que a dependência dos jovens aos pais trata-se de um elemento importante, seja ela emocional ou econômica. 


\section{CONTEXTO ESCOLAR}

Outro dado relevante acerca da gravidez entre os adolescentes refere-se à inclusão escolar, à medida que, de acordo com o que propõem Spíndola et al (2012), as gestantes que não estão mais na escola, tendem a não utilizar métodos contraceptivos, muitas vezes por falta de informação e, inclusive, pela falta de estímulo para a realização de pesquisas na internet (utilizada nas escolas como ferramenta de aprendizado), a qual é citada por muitas jovens como uma fonte de informação sobre contracepção. Informação semelhante é mencionada por Patias e Dias (2014) e Belo e Silva (2004).

Por outro lado, Tavares et al. (2012) salientam que o preconceito e a vergonha advindos do julgamento de outros adolescentes, bem como por parte de professores e da sociedade contribui para o abandono escolar durante a gestação. Foi constatado, também, que há menor frequência de citações do aborto nas instituições particulares, fato que, no entendimento de Correia et al. (2011), pode estar relacionado à dificuldade em falar sobre a sexualidade e seus aspectos, o que pode ter ocorrido nessas escolas.

Numa via similar, os estudos indicam que a inserção em escolas privadas se relaciona a menor frequência de citações do aborto. Todavia, esta informação aparece nos artigos sem que seja suficientemente explorada e é preciso ter o cuidado para não a interpretar sem levar em conta a subnotificação de abortos induzidos que não resultam em complicações de saúde, situação mais provável entre aquelas adolescentes que encontram meios de realizar aborto em clínicas com condições sanitárias adequadas e aparato financeiro para realizar aborto medicamentoso. No que diz respeito às diferenças existentes entre instituições escolares públicas e privadas, verificou-se que, apesar de alguns artigos tomarem as escolas privadas como campo de coleta de dados, a maioria dos estudos apresenta mais informações e dedica mais espaço para relatar aspectos referentes às adolescentes de baixa renda e escolaridade e que estudam em escolas públicas. Há estudos que, inclusive, situam a amostra quanto à classe econômica desfavorecida (ou empobrecida), mas não indicam se os participantes estudam em escola pública ou privada.

Diante disso, avançando nas sugestões dos autores analisados, pode-se acrescentar aspectos relativos à amostra(gem) e delineamento de pesquisa, tais como (a) investigação aprofundada e comparativa entre estudantes de escola pública e privada, considerando, igualmente, o nível socioeconômico, observando em que pontos estas duas realidades convergem e divergem, (b) inclusão de adolescentes homens nas amostras de estudos que explorem as representações sobre aborto e (c) inserção de uma perspectiva interseccional que leve em conta as relações entre geração, gênero, recorte racial/étnico. 


\section{RELIGIÃO}

A religião aparece como outro fator contextual importante, no que se refere à contracepção e práticas sexuais, tal como apontam Camargo e Ferrari (2009), ao indicarem que a prática da masturbação, mesmo após as oficinas de prevenção, ainda era considerada um ato "pecaminoso" por muitos adolescentes. Belo e Silva (2004), numa direção semelhante, ao relacionarem conhecimento espontâneo dos métodos anticoncepcionais e algumas características sociodemográficas, notaram que as adolescentes que possuíam alguma religião entendiam mais sobre o uso de métodos contraceptivos.

Inclusive, a carência de planejamento familiar se encontra relacionada com a questão da religiosidade do sujeito. Os preceitos da doutrina cristã persistem na cultura, ao orientar as ações na esfera da sexualidade e da contracepção e, ainda que carregados de preconceitos, são adotados como naturais. Logo, as decisões sobre planejamento familiar tomam forma de acordo com padrões familiares apoiados em valores morais e religiosos tradicionais. Ou seja, o comportamento adotado pelas mulheres corresponde ao enfoque do planejamento familiar centrado em responsabilizar a mulher, o que garante continuidade à relação de gênero, na qual o homem é o provedor e quem decide, e a mulher a que serve e obedece (Ferreira et al., 2010).

\section{CONTRACEPÇÃO E MÉTODOS CONTRACEPTIVOS: EVIDÊNCIAS DOS ESTUDOS}

No que tange às evidências apresentadas nas pesquisas em relação à contracepção e aos métodos contraceptivos, incluída a prática do aborto, conclui-se que os adolescentes citam o uso de métodos contraceptivos de baixa e alta eficácia, como a camisinha masculina, pílula anticoncepcional, injeção anticoncepcional, DIU, coito interrompido (embora não seja recomendado como método pelo Ministério da Saúde) e, com menos frequência, a pílula do dia seguinte. Também são citados tanto o uso de métodos de baixa, quanto de alta eficácia, tais como camisinha masculina e pílula anticoncepcional (Fonseca et al., 2015), injeção anticoncepcional, DIU, coito interrompido e, com menor frequência, a pílula do dia seguinte (Mendes et al., 2011; Queiroz et al., 2016; Ferrari \& Peres, 2020; Ferrari et al., 2018).

Identificou-se que as adolescentes que vivem relacionamentos mais estáveis, independente da condição econômica e escolar, priorizam a prevenção de gestação, ao invés das DST e HIV/aids, e preferem outros métodos contraceptivos para além da pílula. Nesse sentido, as IST e DST são temáticas apontadas com frequência, com destaque para as vulnerabilidades associadas à sua contração, sobretudo os fatores de risco, tais como o desconhecimento dos métodos contraceptivos e, consequentemente, uso incorreto dos mesmos (Costa et al. 2016; Spindola et al., 2012), fatores que podem aumentar a probabilidade de incidência de gravidez (Neiva-Silva et al., 2018). Ademais, identificou-se que o desconhecimento e uso incorreto dos métodos contraceptivos, o fato de não estudar ou ter parado de estudar, não residir com a família, ter tido mais de 10 parceiros sexuais no último ano, ter parceiro fixo no último ano e ter feito sexo em 
troca de dinheiro ou favores, aparecem como fatores relacionados à gravidez na adolescência e contração de IST e DST (Moreira et al., 2018; Neiva-Silva et al., 2018).

No que tange ao aborto, sua prática aparece relacionada à iniciação sexual (Pirotta \& Schorb, 2002; Spindola et al., 2012; Ferrari et al., 2018), à pobreza (Pirotta \& Schor, 2004), à vivência na rua (Ferrari et al., 2018; Neiva-Silva et al., 2018), ao estupro (Correia et al., 2011; Spíndola et al., 2012) e à experiência de gravidez anterior (Maranhão et al., 2017). A motivação ao aborto deriva do medo da reação dos pais (Correia et al., 2011), da situação de vivência nas ruas, da incidência de duas ou mais experiências de gravidez, do conhecimento reduzido sobre contracepção, da gravidez indesejada, bem como da dificuldade de acesso a diferentes métodos contraceptivos (Neiva-Silva et al., 2018). Acerca dos aspectos psíquicos relacionadas à ocorrência de aborto, Moreira e Sarriera (2006) sustentam que o fato de ter praticado um aborto pode ser considerado uma variável que prediz o mal-estar, ao argumentarem que as adolescentes que já realizaram algum aborto apresentam deterioração no seu estado de saúde e bem-estar maior do que as que não o realizaram, o que causa maior desconfiança no próprio desempenho como mães.

\section{PRODUÇÃO DE CONHECIMENTOS E COMUNICAÇÃO EM SAÚDE}

No que tange à contracepção, evidenciam-se preocupações e ações relativas à falta de conhecimento e uso correto dos métodos contraceptivos e sobre os efeitos do uso de anticoncepcionais (Spíndola et al., 2012; Brêtas \& Silva, 2012). As ações educativas revelam este enviesamento, o que dificulta a apreensão de conhecimentos por parte dos adolescentes e contribui para a compreensão da contracepção como medida e/ou uso de algum método para evitar a gravidez (Brêtas \& Silva, 2002).

A carência e o diálogo reduzido acerca da contracepção são apontados como entraves à aquisição de conhecimentos sobre contracepção pelos adolescentes. Como consequência, o uso incorreto, ou ineficaz, dos métodos é considerado fruto da falta de informação (Spíndola et al., 2012), medo da reação dos pais ao descobrirem a atividade sexual, dificuldade de acesso aos métodos, falta de dinheiro para comprar, medo e vergonha de ir aos serviços públicos que distribuem contraceptivos, além de crenças sobre seus efeitos colaterais (Bié et al., 2006; Patias \& Dias, 2014).

As fontes de informação acerca da contracepção mais apontadas pelos adolescentes foram a família, a escola e os amigos (Alves \& Brandão, 2009; Moura et al., 2011; Ferrari et al., 2018), fato que levanta um questionamento sobre a atuação dos profissionais de saúde, que parece ser restrita. Enquanto as adolescentes obtêm conhecimento sobre os métodos com amigas, irmãs, revistas, televisão e pela internet, os adolescentes meninos obtêm informações com amigos, revistas e TV, enquanto há poucos relatos sobre conversas com a mãe (Alves \& Brandão, 2009). Este fato pode estar vinculado à figura da mulher e da mãe como as fontes de conhecimento e figuras responsáveis pela contracepção, 
sendo a figura paterna relegada a segundo plano, o que reforça a questão da construção social dos papéis masculino e feminino, já que cabe à mãe a incumbência de informar, educar e formar os filhos, sejam estes pertencentes ao seu gênero ou não (Pelloso et al., 2008).

Os meios de comunicação foram citados como fontes importantes de informações para a escolha do método contraceptivo (Bié et al., 2006; Moreira et al., 2011; Patias \& Dias, 2014). No entanto, esses canais interpessoais de comunicação poderiam ser melhor utilizados, por meio de adequada orientação e treinamento dos líderes naturais da comunidade e da própria família do adolescente (Moura et al., 2011) Outra figura citada como fonte de informação é a professora, figura de destaque no grupo de adolescentes gestantes. Pode-se pensar que a escola tem sido responsabilizada por fornecer, além da educação formal, educação informal sobre outros temas presentes em seu cotidiano (Patias \& Dias, 2014).

Em relação à gravidez, as amigas foram as mais citadas como fontes de informação, diálogo e conhecimento, seguidas das mães e parceiros (Bié et al., 2006; Patias \& Dias, 2014). A orientação sobre como evitar gravidez e IST antes da primeira relação sexual, foi mais frequentemente dada na escola que pelos pais, sendo reduzido o percentual de jovens que procuraram orientações em serviços de saúde antes de ter a primeira relação sexual (Maranhão et al., 2017).

A partir do entendimento do papel da escola enquanto fonte de informação e conhecimento relativos à contracepção, compreende-se que esta pode desempenhar uma função importante nesse cenário (Patias \& Dias, 2014). No entanto, há necessidade de que os professores sejam qualificados, pois a análise da postura da escola e dos professores quando se trata de educação sexual, tem mostrado que estes reconhecem a importância do tema, porém a maioria não possui conhecimentos suficientes para promover orientação sexual aos adolescentes, à medida que recebem maior destaque os aspectos biológicos da sexualidade, em detrimento dos sentimentos e valores que a envolvem (Moura et al., 2011).

Poucos são os programas voltados aos pais para ensiná-los a dialogar, tirar dúvidas e orientar os filhos no que se refere à sexualidade e contracepção. Apesar da dificuldade encontrada pelos pais, ter comunicação positiva com os pais proporciona suporte emocional e sentimento de apoio e, portanto, figura como um fator protetor para o jovem. Percebe-se, portanto, a importância do apoio da família nas ações de promoção da saúde sexual e reprodutiva de adolescentes e jovens, por meio do incentivo ao uso dos serviços de planejamento familiar e de métodos contraceptivos (Moura \& Gomes, 2014).

Diante disso, foi sinalizado que as ações de educação sexual e reprodutiva devem incluir diversos atores sociais, buscando envolver os jovens de um modo geral e não somente as adolescentes do sexo feminino. Ao longo do desenvolvimento de oficinas de educação sexual e reprodutiva, a busca pelo trabalho contínuo deve ser empreendida, em virtude de que o desconhecimento sobre os métodos 
anticoncepcionais existentes persiste após as intervenções (Camargo \& Ferrari, 2009; Queiroz et al., 2016). Nesse viés, as ações de educação sexual deveriam abordar outros temas, para além do uso de métodos contraceptivos e prevenção de IST, dado que o interesse dos adolescentes se estende sobre os riscos e a prática de sexo durante e após a gravidez, informação sobre o aborto e sobre a saúde física e mental da mulher (Brêtas \& Silva, 2002).

Diante disso, alerta-se para educação sexual enquanto responsabilidade coletiva, a ser compartilhada entre educadores, profissionais de saúde, além dos pais (Queiroz et al., 2016). Dada a importância que os adolescentes dão para o conhecimento do corpo e busca pela descoberta de sua sexualidade, independente se for o seu ou o do sexo oposto, o interesse pelo conhecimento deve ser incentivado cada vez mais (Camargo \& Ferrari, 2009; Spínola et al., 2017). Os estudos também avisaram que os professores se prendem mais aos aspectos biológicos da sexualidade que nos sentimentos e valores que a envolvem. Sob este aspecto, se o que se pretende é uma educação sexual que respeite os jovens na sua integralidade, e promova sua emancipação e protagonismo, é necessário que os próprios professores participem de processos de educação permanente que possibilitem a reflexão sobre suas experiências de vida e potencializem a reconfiguração de suas representações e práticas acerca das adolescências e das sexualidades.

Nesse viés, no que diz respeito às concepções sobre adolescência presentes nos estudos analisados, evidencia-se o viés biológico, associado aos fatores hormonais e cronológicos da "fase da adolescência". Desse modo, percebe-se que a maioria das investigações ressalta o ser adolescente a partir de uma conotação desenvolvimentista (embora tal abordagem seja relevante cientificamente, o que parece digno de nota, é que tal enquadre inviabiliza outras formas de conceber, olhar e compreender o ser/estar adolescente), determinando-se adolescência mediante elementos biológicos e cronológicos. Desse modo, não raro, a gravidez é concebida como experiência a ser evitada, e não como acontecimento genuíno, fruto de escolhas e desejos.

A ênfase nos aspectos biológicos, fisiológicos e cronológicos resulta em práticas relativas à educação sexual voltadas, majoritariamente, à "gravidez na adolescência", esta considerada precoce e/ou indesejada. Tal enquadre parece conceber o/a adolescente como alguém que (agora) possui um corpo apto à reprodução, embora não seja indicado que isso aconteça. No entendimento de Menandro, Trindade e Almeida (2003), embora haja avanços na compreensão dos direitos dos(as) adolescentes, bem como maior reconhecimento dessa população enquanto classe e grupo social, percebe-se, ainda, a vigência de uma concepção de adolescência enquanto período com características fixas, naturalmente constituinte do desenvolvimento humano, presente em produções dos meios de comunicação, na compreensão popularmente difundida e compartilhada do que seja a adolescência, e mesmo em algumas das proposições originárias de setores da Psicologia. 
Mediante uma perspectiva crítica, torna-se crucial colocar em evidência o(s) "lugar(es)" que os adolescentes estão ocupando nos discursos das ciências, no senso comum e nos espaços que frequentam em seu cotidiano, incluindo no que se refere às práticas contraceptivas, à educação sexual e intervenções relacionadas à sexualidade dessas pessoas. Nessa direção, acredita-se que o uso do termo "adolescências" (no plural) é mais sensível à noção de multiplicidade que o impregna. Esta multiplicidade denota que cada pessoa que "adolesce" é única, fruto de uma história de vida que produz formas singulares de ser, estar e se relacionar com/no mundo. Desse modo, para além das transformações físicas, psicológicas e sociais, as adolescências devem ser repensadas como fabricação social, isto é, elas são influenciadas por interpretações e significações produzidas na/pela sociedade. Ao tomarem forma de um processo, de "devir", as adolescências constituem um vir-a-ser, transformar-se, metamorfosear-se, construídas e modificadas mediante experiências permeadas pelo contexto sociocultural (Ozella \& Aguiar, 2008; Berni \& Roso, 2014; Campos et al., 2017).

\section{INIQUIDADES DE GÊNERO: (IN)DIFERENÇAS EM CENA}

Em relação às questões de gênero, há nítida presença de iniquidades, competindo às mulheres a responsabilidade pela reprodução (gravidez, planejamento familiar, uso de métodos), pelos diálogos e esclarecimentos junto aos filhos a respeito da contracepção, reforçando construções sociais da categoria gênero. As fontes de informação acerca da contracepção mais apontadas pelos adolescentes são a escola (majoritariamente), a família, os(as) amigos(as), professoras e meios de comunicação.

Assim, as diferenças no modo como as temáticas relacionadas à contracepção (métodos contraceptivos, gravidez, aborto, fatores de risco para contração de IST/DST/HIV/aids, entre outros) são abordadas entre homens e mulheres, evidenciam que as práticas contraceptivas são tomadas como responsabilidade das mulheres. Nessa perspectiva, Gubert e Madureira (2008) argumentam que o fato de a adolescente tomar pílula, mostra a contracepção como preocupação central que, ao ser assumida pela mulher, desobriga o homem do uso do preservativo.

Se por um lado há menor uso de preservativo pelas mulheres, por outro a negligência com prevenção/contracepção é justificada pelos homens em discurso que enfoca uma suposta incompatibilidade entre desejo sexual e controle e que atribui essa responsabilidade à mulher (Baptista et al., 2012). Para os homens, a mulher tem capacidade de autocontrole no sexo e o fato de estar desprevenido não é razão para que a relação não ocorra. Da mesma forma, justificam o não uso em relações eventuais como uma tomada de risco (prova de masculinidade) e, em relações estáveis, atribuem a responsabilidade à parceira (Gubert \& Madureira, 2008).

Nesse viés, percebe-se que a adoção de medidas contraceptivas entre adolescentes é fortemente influenciada pelas questões de gênero. No que tange à 
negociação no uso do contraceptivo, muitas vezes, a decisão acaba colocando a mulher no papel de submissa. Dessa maneira, o sexo desprotegido torna-se rotineiro na trajetória sexual das jovens. Assim, a dinâmica do sexo sem proteção/arrependimento parece repetir no comportamento e nos discursos (Ferrari \& Peres, 2020; Ferrari et al., 2018).

Tais constatações permitem indagar sobre o motivo que leva a adolescente a não conseguir impor a sua vontade ao parceiro. Este fato, possivelmente, pode caracterizar-se como uma condição que expressa iniquidade de gênero e pode ser identificada como violenta e desigual (Ferrari et al., 2018). Todavia, se a mulher se protege frente ao intercurso sexual, pode ver-se mal diante dos olhos masculinos [sic] (Patias \& Dias, 2014). Afinal, a sociedade impõe o sexo de formas diversificadas para os diferentes gêneros, ao mostrar para o menino o ato sexual como certo e, para a menina, como algo errado (Schor et al., 2007).

Numa direção similar, a preocupação com a gravidez na primeira relação é pouco demonstrada pelos homens. O uso da camisinha ainda está muito subordinado ao desejo e aval do marido e, desse modo, às vezes, as mulheres querem fazer uso, mas eles (os companheiros) não permitem. Esse fato leva muitas mulheres a recorrerem ao uso de injeção, sem o conhecimento do marido, para que ele, ao pensar que a parceira não faz uso de nenhum método contraceptivo, continue usando a camisinha (Alves \& Brandão, 2009).

Portanto, a gravidez assume sentidos e responsabilidades diversos, quando de sua incidência entre adolescentes. Culturalmente, a mulher costuma assumir mais responsabilidades no que concerne ao âmbito "doméstico" e, diante da descoberta da gravidez, a adolescente atravessa uma mudança na sua rotina de estudos, de trabalho e de lazer, bem como assume precocemente maiores responsabilidades. Ocorre a ruptura dos projetos pessoais, afastamento da escola e das interações sociais em decorrência da gravidez (Queiroz et al., 2016). No entanto, a gravidez na adolescência não é um acontecimento exclusivo às mulheres, sendo necessário envolver os homens, como forma de buscar uma resolução para o problema. Há necessidade de mudança de cultura das ações de planejamento familiar e saúde reprodutiva, as quais são, na maioria das vezes, voltadas unicamente para mulheres (Moura \& Gomes, 2014).

Diante do exposto, as normas sociais de sexualidade e reprodução/contracepção incidem, quase que exclusivamente sobre as mulheres. Por exemplo, ela assume sozinha a responsabilidade sobre a saúde sexual e reprodutiva. A escolha e uso de métodos contraceptivos cabe à mulher, a qual submete-se, muitas vezes, aos efeitos indesejados sobre sua saúde (Ferreira et al., 2010; Spínola et al., 2017). Outra tradição mantida que afeta as relações de gênero e reflete a cultura machista refere-se à prática sexual. Espera-se que os homens iniciem logo na "entrada" da adolescência, enquanto o mesmo não é recomendável para as mulheres (Alves $\&$ Brandão, 2009; Bié et al., 2006). 
O processo de construção social, histórica e cultural das representações do masculino e feminino na prática social também expressa diferenças significativas de como o adolescente vive e pensa. As imbricadas relações de gênero fazem das meninas um grupo socialmente mais vulnerável dos que os meninos, pois ainda se sentem incapazes de negociar o uso do preservativo nas práticas sexuais, principalmente por influência do namorado, por terem confiança no parceiro (Camargo \& Ferrari, 2009).

Identificou-se, ainda, reflexões a respeito do quanto a compreensão acerca das masculinidades pode causar vulnerabilidades, à medida que o atributo da masculinidade, mensurável por meio do desempenho sexual, não comporta um momento de interrupção ou mesmo negociação do preservativo, visto que se considera que algo pode sair do controle e o desempenho durante a relação ser ameaçado, o que pode comprometer a própria masculinidade (Alves \& Brandão, 2009). Por outro lado, Gubert e Madureira (2008) relatam que o caráter não programado das relações remete à masculinidade hegemônica, segundo a qual o homem não deve dizer não a uma possibilidade de manter relação sexual, mesmo que, com isso, se exponha a riscos.

A precocidade da iniciação sexual, na compreensão de Baptista et al. (2012), em um sistema de valores que destaca as características hegemônicas da masculinidade, permite ao adolescente mostrar-se mais viril, mais másculo, mais homem para os demais. A iniciativa e a experiência vinculada a um maior número de parceiras são comportamentos que fazem parte da sexualidade entendida como "masculina", ao passo que a espera, a menor experiência sexual e o resguardo físico são atributos que constituem a natureza e a sexualidade femininas (Borges \& Schor, 2005).

Por outro lado, o relato de algumas adolescentes reflete a ambivalência entre o desejo e a norma social ainda vigente em alguns contextos sociais, que considera a iniciativa como prerrogativa masculina, enquanto as mulheres devem resistir para posteriormente ceder (Pirotta \& Schor, 2004), bem como qualificação da mulher como confiável ou descartável, devido à vida sexual ativa (Gubert \& Madureira, 2008). O uso da camisinha entre os adolescentes está associado às relações esporádicas e/ou com mulheres sem um conhecimento prévio. Quando se trata da namorada ou esposa, a camisinha é substituída pela confiança, casos em que se utiliza a pílula para evitar a gravidez. Adquirir alguma doença não está em pauta (Alves \& Brandão, 2009).

Por outro lado, no que concerne ao uso da expressão "gênero", evidenciou-se a predominância de um enquadre teórico/epistemológico baseado no binarismo de gênero (sexo feminino e sexo masculino) na maior parte dos estudos incluídos na revisão. Isto é, muitos autores entendem gênero como sinônimo de sexo, dividindo as relações entre homens e mulheres em dois eixos distintos e desconectados, onde masculino $=$ homem e feminino $=$ mulher, não considerando que, para além 
dos elementos biofisiológicos, as dimensões socioculturais, estruturais, institucionais e subjetivas fabricam múltiplos modos de expressão de gênero.

Sob a perspectiva dos direitos sexuais e reprodutivos, Corrêa (1990) alerta que "A fusão conceptual entre gênero e sexualidade torna muito problemática nossas operações teóricas e políticas sem relação aos direitos sexuais" (p.45). O binarismo não dá conta do desejo, do erotismo, das experiências de prazer, do agenciamento sexual. Por isso, segue a autora, é preciso alterar a linguagem do singular (modelo dos dois sexos) para "sexualidades" (p. 46).

Certamente, o intuito não é criticar os autores que adotam o enquadre do binarismo de gênero, pois considera-se que esta é uma forma legitimada teoricamente, mas sugere-se que se amplie as possibilidades de entendimento de gênero, enquanto potência que possibilita a desestabilização de categorias como sexo=gênero, heterossexualidade hegemônica e compulsória, e "ideologia de gênero", expressão utilizada de modo distorcido por atores governamentais e difundida amplamente por atores sociais que defendem "posições tradicionais, reacionárias e fundamentalistas em relação aos papéis de gênero do homem e da mulher, afirmando que "ideologia de gênero significa a desconstrução dos papéis tradicionais de gênero" (Reis \& Eggert, 2017, p.17). Ao contrário, educadores e ativistas progressistas almejam "defender a igualdade de gênero via "erradicação das iniquidades de gênero, que fazem uma distinção binária entre masculino e feminino, relegando o feminino a um plano inferior, estabelecendo papéis inflexíveis de gênero (Reis \& Eggert, 2017, p.20).

Quanto ao aborto, evidenciou-se que a participação do homem contribuiu para a tomada de decisão sobre a prática. Além de atuarem de forma incisiva com ameaças físicas e emocionais, os homens oferecem apoio financeiro para comprar medicamentos com propriedade abortiva ou para custear o procedimento em clínicas clandestinas. A pressão e as ameaças realizadas pelo parceiro constituemse elementos fundamentais para que as jovens "concordem" com o aborto, demonstrando que o contexto afetivo-amoroso detém centralidade para o desfecho do evento reprodutivo (Ferrari \& Peres, 2020; Ferrari et al., 2018).

Diante disso, buscar um relacionamento que possa ser mais equânime entre os gêneros torna-se essencial, com a finalidade de garantir os direitos sexuais e reprodutivos das mulheres, principalmente daquelas que se encontram em condições de maior vulnerabilidade, mulheres jovens, pobres e negras, cujas escolhas e vontades são desrespeitadas e silenciadas (Ferrari \& Peres, 2020; Ferrari et al., 2018).

Em relação à participação dos serviços de saúde na manutenção e/ou perpetuação de inequidade de gênero, a procura pelo serviço de saúde é evitada pelos adolescentes por medo da exposição na comunidade em que mora, o que revela o constrangimento diante de situações delicadas de saúde. Este fato põe em cena que, em geral, os jovens não encontram espaços preparados para recebê-los nas 
unidades de saúde, bem como os profissionais de saúde nem sempre estão habilitados para atender as demandas desse público (Alves \& Brandão, 2009).

No que tange à realização do Pré-Natal, Tavares et al. (2012) alertam que o período de início da realização do mesmo mostrou-se inadequado devido às adolescentes terem dificuldades para reconhecer que estavam grávidas. $O$ susto advindo com a descoberta da gravidez tende a levar a adolescente a esconder a gestação, sobretudo da família, fato que culmina no adiamento da assistência pré-natal.

\section{LIMITAÇÕES E SUGESTÕES ENCONTRADAS NOS ESTUDOS ANALISADOS}

Entre as limitações encontradas no conjunto de artigos analisados, destacam-se o viés recordatório de memória dos participantes (Moreira et al., 2018) , a fragilidade do instrumento de entrevista (Belo \& Silva, 2012), coleta de dados em sala de aula (Gubert \& Madureira, 2008), impossibilidade de apontar causalidade (Spínola et al., 2017), uso de instrumento questionário (em detrimento de espaços de discussão e compartilhamento de práticas, saberes e representações), tabus morais e religiosos em relação ao aborto (Correia et al., 2011) e inviabilidade de generalização, em decorrência da amostra (Pirotta \& Schor, 2004).

Estas limitações apontadas pelos estudos possibilitaram a elaboração de sugestões no trabalho direto com os adolescentes, sumarizadas a seguir. Em relação aos métodos de pesquisa sugere-se a utilização de questionário autoaplicável como estratégia de abordagem para temas difíceis de serem relatados (Correia et al., 2011), a utilização da coleta de dados por entrevistadoras mulheres (no caso de pesquisas sobre a temática do aborto), já que esta estratégia é capaz de reduzir as possibilidades de uma resposta não verdadeira, assim como a aplicação de um curto intervalo de tempo decorrido entre o evento de interesse e o momento da entrevista (Spínola et al., 2017).

Em relação às iniquidades de gênero, considerar as influências de relações desiguais e assimétricas de gênero ainda vigentes na cultura brasileira (Ferrari et al., 2018), compreender o uso de anticoncepcionais como uma responsabilidade mútua, não apenas delegada às adolescentes mulheres (Pelloso et al., 2008), proporcionar espaço para que o adolescente possa falar de si, trocar experiência e apreender informações corretas que favoreçam a adoção de hábitos de vida saudáveis (Queiroz et al., 2016), capacitar os adolescentes como agentes multiplicadores, bem como estabelecer a articulação entre os setores saúde e educação (Mendes et al., 2011), e reconhecer os adolescentes como pessoas em sua totalidade, com suas histórias, suas experiências e suas vivências sexuais (Cerqueira-Santos et al., 2010).

Em relação aos serviços de saúde, foi recomendado avaliar a qualidade e as estratégias utilizadas pelos profissionais que trabalham com os adolescentes, assim como revelar quais diretrizes são apropriadas e aplicadas por estes (Farias \& Moré, 2011). Nas unidades de saúde, evidenciou-se a necessidade de estreitamento dos vínculos entre profissionais e adolescentes na perspectiva de construir um 
conhecimento sobre os assuntos tratados, que considere as experiências dos jovens e os saberes trazidos pelos profissionais, além de considerar o adolescente como sujeito de direitos, tendo sua intimidade preservada na relação com o profissional de saúde (Alves \& Brandão, 2009) e a criação de grupos educacionais ao longo do pré-natal e a extrapolação para os grupos educacionais para promoção da saúde, para além do período gestacional (Borovac-Pinheiro et al., 2019).

A parceria entre escola-serviço de saúde-família foi ressaltada como necessária à promoção da saúde sexual e reprodutiva dos adolescentes (e.g., Moura et al., 2011; Correia et al., 2011). Para a redução nos índices de morbidade e mortalidade materna, esta parceria também deverá levar em conta as questões relacionadas à prática do aborto entre as adolescentes (Moura et al., 2011)

\section{CONSIDERAÇÕES FINAIS}

A partir da apreciação de investigações realizadas no contexto brasileiro a respeito da prática contraceptiva entre os adolescentes, identificou-se marcante associação desta ao uso (correto e incorreto) de métodos contraceptivos, à gravidez na adolescência/gravidez precoce, ao conhecimento e prevenção de ISTs e DSTs, à iniciação sexual "precoce" e à temática aborto. Revelou-se, também, a presença de viés relacionado à construção social da categoria gênero, enquanto masculino (homem) e feminino (mulher).

Destaca-se a conexão entre menor poder aquisitivo e maior índice de experiências de gravidez, bem como de desconhecimento acerca do uso correto de métodos contraceptivos e instituições escolares públicas. Todavia, frente ao índice significativo de estudos empreendidos junto às escolas públicas na amostra analisada, considera-se conveniente a execução de investigações futuras na esfera privada de ensino.

A imprescindibilidade de estudos relativos à associação entre nível socioeconômico e prática de aborto advém do fato de que a maioria dos estudos tende a descrever variáveis e consequências que concernem às adolescentes de baixa renda. Salienta-se, no entanto, que, embora alguns estudos apontem as adolescentes com menor poder aquisitivo como aquelas que engravidam mais, é possível indagar se as que possuem poder aquisitivo maior engravidam menos por fazerem mais abortos. Outro tema importante de ser abordado por futuras investigações, diz respeito às questões relacionadas à raça/etnia e contracepção, assim como acerca das influências da religião sobre a contracepção, bem como investigações abordando o uso de métodos contraceptivos alternativos entre adolescentes (contraceptivo masculino, tabelinha, entre outros).

A partir das limitações dos estudos, torna-se essencial a realização de ações/intervenções em educação sexual, as quais possam contar com a participação de adolescentes (principalmente nas modalidades de grupos de 
discussão, seminários e fóruns de discussão entre adolescentes, pais e adolescentes e profissionais de saúde, assistência e educação), enquanto participantes de pesquisa, à medida que a maioria dos estudos analisados foi empreendido por meio do uso de questionários e de entrevistas com perguntas fechadas.

Por fim, compreende-se, então, a essencialidade da educação sexual estar presente nas escolas, não apenas como dimensão curricular a ser trabalhada pelos professores, mas, também, como temática salutar a ser discutida, articulada e empreendida em espaços coletivos, que contem com a presença de pais, profissionais e serviços de saúde, assistência e educação e adolescentes, considerando sua liberdade de expressão e autonomia.

\section{REFERÊNCIAS}

*Alves, C. A. \& Brandão, E. R. (2009). Vulnerabilidades no uso de métodos contraceptivos entre adolescentes e jovens: interseções entre políticas públicas e atenção à saúde. Ciência \& Saúde Coletiva, 14(2), 661-670. https://doi.org/10.1590/S1413-81232009000200035

*Baptista, C. J., Maciel, A. G., Caldeira, A. P., Tupinambás, U., \& Greco, D. B. (2012). Prevalência de fatores de vulnerabilidade juvenil às DST/ HIV/ AIDS: Estudo com enfoque de gênero no Norte de Minas Gerais, Brasil, 2008-2009 Motricidade, Edições Desafio Singular Vila Real, Portugal 8(2), 177-186.

*Belo, M. A. V. \& Silva, J. L. P. (2004). Conhecimento, atitude e prática sobre métodos anticoncepcionais entre adolescentes gestantes. Revista de Saúde Pública, 38(4), 479-487. https://doi.org/10.1590/S0034-89102004000400001

Berni, V. L. \& Roso, A. (2014). A adolescência na perspectiva da psicologia social crítica. Psicologia \& Sociedade, 26(1), 126-136. https://doi.org/10.1590/S0102-71822014000100014

*Bié, A. P. A., Diógenes, M. A. R., \& Moura, E. R. F. (2006). Planejamento familiar: o que os adolescentes sabem sobre este assunto? Revista Brasileira em Promoção da Saúde. 19(3), 125-130.

Bolsonaro, J. M. (2018) Live Presidente Jair Messias Bolsonaro. Recuperado de https://www.facebook.com/watch/live/?v=249737109031557\&ref=watch_permalink.

Borges, R. O. \& Borges, Z. N. (2018). Pânico moral e ideologia de gênero articulados na supressão de diretrizes sobre questões de gênero e sexualidade nas escolas. Revista Brasileira de Educação, 23(1), 1-23. https://doi.org/10.1590/S1413-24782018230039

*Borovac-Pinheiro, A., Jesus, E. A. R., \& Surita, F. G. (2019). Empowering Adolescent Mothers in the Choice of Contraceptive Methods at the Postpartum Period: Avoiding a Subsequent Pregnancy. Revista Brasileira de Ginecologia e Obstetrícia, 41(10), 607-612. https://doi.org/10.1055/s-0039-1697985

*Brêtas, J. R. S. \& Silva, C. V. (2002). Interesse de escolares e adolescentes sobre corpo e sexualidade. Revista Brasileira de Enfermagem, 55(5), 528-534. https://doi.org/10.5935/00347167.20020069

*Camargo, E. A. I. \& Ferrari, R. A. P. (2009). Adolescentes: conhecimentos sobre sexualidade antes e após a participação em oficinas de prevenção. Ciência \& Saúde Coletiva, 14(3), 937-946. https://doi.org/10.1590/S1413-81232009000300030

Campos, H. M., Paiva, C. G. A., Mourthé, I. C. A., Ferreira, Y. F., \& Fonseca, M. C. (2017). Direitos humanos, cidadania sexual e promoção de saúde: diálogos de saberes entre pesquisadores e adolescentes. Saúde em Debate, 41(113), 658-669. https://doi.org/10.1590/01031104201711324

${ }^{*}$ Canavez, M. F., Soares, E., Silva, N. K. S. M., \& Chaves, P. M. (2010). Gravidez precoce na concepção dos adolescentes. Revista de Pesquisa Cuidado é Fundamental Online, 2(ed. supl.), 477-480. https://doi.org/10.9789/2175-5361.2010.v0i0.\%25p 
*Cerqueira-Santos, E.; Paludo, S. S.; Schiró, E. D. B., \& Koller, S. H. (2010). Gravidez na adolescência: análise contextual de risco e proteção. Psicologia em Estudo, 15(1), 73-85. http://dx.doi.org/10.1590/S1413-73722010000100009

Corrêa, S. (1999). "Saúde reprodutiva", Gênero e sexualidade: legitimação e novas interrogações. In K. Giffin \& S. H. Costa. (Orgs.). (1999). Questões da saúde reprodutiva (pp. 19-38). Rio de Janeiro: FIOCRUZ.

${ }^{*}$ Correia, D. S., Cavalcante, J. C., Egito, E. S. T., \& Maia, E. M. C. (2011). Prática do abortamento entre adolescentes: um estudo em dez escolas de Maceió (AL, Brasil). Ciência \& Saúde Coletiva, 16(5), 2469-2476. https://doi.org/10.1590/S1413-81232011000500016

${ }^{*}$ Costa, G. P. O., Guerra, A. Q. S., \& Araújo, A. C. P. F. (2016). Conhecimentos, atitudes e práticas sobre contracepção para adolescentes. Journal of Research Fundamental Care Online, 8(1), 3597 3608. https://doi.org/10.9789/2175-5361.2016.v8i1.3597-3608

Desideri, L. \& Kadanus, K. Exclusivo: Damares Alves fala sobre sexo precoce, "novo Bolsa Família" e pressões da esquerda. Gazeta do Povo, 2019 (17 de dez). Recuperado de https://www.gazetadopovo.com.br/vida-e-cidadania/exclusivo-damares-alves-sexo-entrejovens-bolsa-familia-pressoes-esquerda/?utm_source=facebook\&utm_medium =midiasocial\&utm_campaign=gazeta-do-povo

Dias, E. G., Alves, J. C. S., Viana, J. M., Santos, I. M., \& Silva, J. P. (2015). Percepções sobre a gravidez em um grupo de adolescentes grávidas do município de Janaúba-MG. Revista Eletrônica Gestão \& Saúde, 6(2), 1239-1253. http://dx.doi.org/10.18673/gs.v6i2.22466

Ercole, F. F., Melo, L. S., \& Alcofarado, C. L. G. C. (2014). Revisão integrativa versus revisão sistemática. Revista Mineira de Enfermagem, 18(1), 9-11. http://www.dx.doi.org/10.5935/1415 2762.20140001

Farias, R. \& Moré, O. O. (2012). Repercussões da gravidez em adolescentes de 10 a 14 anos em contexto de vulnerabilidade social. Psicologia: Reflexão e Crítica, 25(3), 596-604. https://doi.org/10.1590/S0102-79722012000300020

*Ferrari, W. \& Peres, S. (2020). Itinerários de solidão: aborto clandestino de adolescentes de uma favela da Zona Sul do Rio de Janeiro, Brasil. Cadernos de Saúde Pública, 36(1), 1-14. https://doi.org/10.1590/0102-311X00198318

*Ferrari, W., Peres, S., \& Nascimento, M. (2018). Experimentação e aprendizagem na trajetória afetiva e sexual de jovens de uma favela do Rio de Janeiro, Brasil, com experiência de aborto clandestino. Ciência \& Saúde Coletiva, 23(9), 2937-2950. https://doi.org/10.1590/141381232018239.11312018

*Ferreira, M. L. S. M., Gonçalves, I. R. G., \& Jamas, M. T. (2010). Comportamiento de mujeres y sus parejas referentes a la planificación familiar. Investigación y Educación en Enfermería Medellín, 28(2), 195-203.

*Fonseca, A. C. N., Gomes, A. T., \& Barreto, J. G. (2015). Distribuição de anticoncepcionais em uma farmácia básica no município de São José do Calçado - ES. Acta Biomedica Brasiliensia. 6(1), $10-20$.

*Gubert, D. \& Madureira, V. S. F. (2008). Iniciação sexual de homens adolescentes. Ciência \& Saúde Coletiva, 13(2): 2247-2256. https://doi.org/10.1590/S1413-81232008000900029

Leite, V. (2019). "Em defesa das crianças e da família": Refletindo sobre discursos acionados por atores religiosos "conservadores" em controvérsias públicas envolvendo gênero e sexualidade. Sexualidad, Salud y Sociedad, 1(39). https://doi.org/10.1590/1984-6487.sess.2019.32.07.a

*Maranhão, T. A., Gomes, K. R. O., Oliveira, D. C., \& Neto, J. M. M. (2017). Repercussão da iniciação sexual na vida sexual e reprodutiva de jovens de capital do Nordeste brasileiro. Ciência \& Saúde Coletiva, 22(12), 4083-4094. https://doi.org/10.1590/1413-812320172212.16232015

Menandro, M. C. S., Trindade, Z. A., \& Almeida, A. M. O. (2003). Representações sociais da adolescência/juventude a partir de textos jornalísticos (1968-1974 e 1996-2002). Arquivos Brasileiros de Psicologia, 55(1), 42-55.

*Mendes, S. S., Moreira, R. M. F., Martins, C. B. G., Souza, S. P. S., \& Matos, K. F. (2011). Saberes e atitudes dos adolescentes frente à contracepção. Revista Paulista de Pediatria, 29(3), 385-91 https://doi.org/10.1590/S0103-05822011000300013

Mendonça, R. C. M. \& Araújo, T. M. E (2009). Métodos contraceptivos: a prática dos adolescentes das Escolas Agrícolas da Universidade Federal do Piauí. Escola Anna Nery, 13(4). 863-871. https://doi.org/10.1590/S1414-81452009000400024 
Moraes, L., Franca, C., Silva, B., Valença, P., Menezes, V., \& Colares, V. (2019). Iniciação sexual precoce e fatores associados: uma revisão da literatura. Psicologia, Saúde \& Doenças, 20(1), 59-73. http://dx.doi.org/10.15309/19psd200105

Moraes, S. P. \& Vitalle, M. S. S. (2015). Direitos sexuais e reprodutivos na adolescência: interações ONU-Brasil. Ciência \& Saúde Coletiva, 20(8), 2523-2531. https://doi.org/10.1590/141381232015208.03112014

*Moreira, B. L. R., Rocha, J. B. T., Puntel, R. L., \& Folmer, V. (2011). Educação sexual na escola: implicações para a práxis dos adultos de referência a partir das dúvidas e curiosidades dos adolescentes. Revista Electrónica de Enseñanza de las Ciencias, 10(1), 64-83.

*Moreira, L. R., Dumith, S. C., \& Paludo, S. S. (2018). Uso de preservativos na última relação sexual entre universitários: quantos usam e quem são? Ciência \& Saúde Coletiva, 23(4), 1255-1266. https://doi.org/10.1590/1413-81232018234.16492016

*Moreira, M. C. \& Sarriera, J. C. (2006). Preditores de saúde e bem-estar psicológico em adolescentes gestantes. Psico-USF, 11(1), 7-15. https://doi.org/10.1590/S1413-82712006000100002

*Moura, L. N. B., Gomes, K. R. O., Rodrigues, M. T. P., \& Oliveira, D. C. (2011). Informação sobre contracepção e sexualidade entre adolescentes que vivenciaram uma gravidez. Acta Paulista de Enfermagem; 24(3), 320-26. https://doi.org/10.1590/S0103-21002011000300003

*Neiva-Silva, I., Demenech, L. M., Moreira, L. R., Oliveira, A. T., Carvalho, F. T., \& Paludo, S. S. (2018), Experiência de gravidez e aborto em crianças, adolescentes e jovens em situação de rua. Ciência \& Saúde Coletiva, 23(4), 1055-1066. https://doi.org/10.1590/141381232018234.11342016

Page, M. J.; McKenzie, J. E; Bossuyt, P. M.; Boutron, I.; Hoffmann, T. C.; Mulrow, C. D.; Shamseer, I.; Tetzlaff, J. M.; Akl, E. A.; Brennan, E. S.; Chou, R.; lanville, J. G.; Grimshaw, J. M.; Hróbjartsson, A.; Lalu, M. M.; Li, T.; Loder, E. W.; Mayo-Wilson, E.; McDonald, S,; McGuinness, L. A.; Stewart, L. A.; Thomas, J.; Tricco, A. C.; Welch, V. A.; Whiting, P., \& Moher, D. (2020). The PRISMA 2020 statement: an updated guideline for reporting systematic reviews. BMJ, 372(71), 1-9. 2021;372:n71. https://doi.org/10.1136/bmj.n71

* Patias, N. D. \& Dias, A. C. G. (2014). Sexarca, informação e uso de métodos contraceptivos: comparação entre adolescentes. Psico-USF, 19(1), 13-22. https://doi.org/10.1590/S141382712014000100003

*Pelloso, S. M., Carvalho, M. D. B., \& Higarashi, I. H. (2008). Sexualidade e gênero: um estudo com adolescentes em um município de pequeno porte do Noroeste do Paraná. Acta Scientiarum. Health Sciences. 30(2), 113-119. https://doi.org/10.4025/actascihealthsci.v30i2.552

Pinheiro, A. S., Silva, R. L. G., \&Tourinho, M. B. A. C. (2018). A Estratégia Saúde da Família e a escola na educação sexual: uma perspectiva de intersetorialidade. Trabalho, Saúde e Educação, 15(3), 803 - 821. https://doi.org/10.1590/1981-7746-sol00084

*Pirotta, K. C. M. \& Schor, N. (2004). Intenções reprodutivas e práticas de regulação da fecundidade entre universitários. Revista de Saúde Pública, 38(4), 495-502. https://doi.org/10.1590/S003489102004000400003

Priotto, E. M. T. P., Fuhr, A. L., Gomes, L. M. X., \& Barbosa, T. L. A. (2018). Iniciação sexual e práticas contraceptivas de adolescentes na tríplice fronteira entre Brasil, Argentina e Paraguai. Revista Panamericana de Salud Pública, 42(7) ,1-9. https://doi.org/10.26633/RPSP.2018.16

*Queiroz, M. V. O., Alcântara, C. M., Brasil, E. G. M., \& Silva, R. M. (2016). Participação de adolescentes em ações educativas sobre saúde sexual e contracepção. Revista Brasileira de Promoção da Saúde, 29(Supl), 58-65. https://doi.org/10.5020/18061230.2016.sup.p58

Reis, T. \& Eggert, E. (2017). Ideologia de gênero: uma falácia construída sobre os planos de educação brasileiros. Revista Educação e Sociedade, Campinas, 38(138), 9-26. https://doi.org/10.1590/ES0101-73302017165522

Russo, K. \& Arreguy, M. E. (2015). Projeto "Saúde e Prevenção nas Escolas": percepções de professores e alunos sobre a distribuição de preservativos masculinos no ambiente escolar. Physis, 25(2), 501-523. https://doi.org/10.1590/\$0103-73312015000200010

*Schor, N., Corbett, C. E. P., Peres, F., Pontilho, P. M., Tanaka, L. F., França, M. N., Cardoso, E. B., \& Costa, N. A. (2007). Adolescência, vida sexual e planejamento reprodutivo de escolares de Serra Pelada. Revista Brasileira de Crescimento e Desenvolvimento Humano, Pará, 17(2), 4553. https://doi.org/10.1590/S0103-73312015000200010

Schreiber, M. (2019). Contra gravidez na adolescência, Damares busca inspiração nos EUA para estimular jovens a não fazer sexo. BBC News Brasil em Brasília. 6 dezembro 2019. Recuperado de https://www.bbc.com/portuguese/brasil-50682336. 
Silva, M. D. T., Ferreira, M. S. V., Amaral-Bastos, M. M.; Monteiro, M. A. J., \& Couto, G. R. (2020). Diagnóstico do conhecimento dos adolescentes sobre sexualidade. Acta Paulista de Enfermagem, 33, 1-7. https://doi.org/10.37689/acta-ape/2020AO0210

*Spindola, T., Siqueira, N. S. B., \& Cavalcanti, R. L. (2012). As gestantes adolescentes e o emprego dos métodos contraceptivos. Revista de Pesquisa Cuidado é Fundamental [Online], 4(1), 26362646.

*Spinola, M. C. R., Béria, J. U., \& Schermann, L. B. (2017). Factors associated with first sexual intercourse among mothers with 14-16 years of age from Porto Alegre/RS, Brazil. Ciência \& Saúde Coletiva, 22(11), 3755-3762. https://doi.org/10.1590/1413-812320172211.00082016

*Tavares, K. O., Paganotto, K. M., Frare, J. C., Carvalho, M. D. B., \& Pelloso, S. M. (2012). Perfil de puérperas adolescentes atendidas em um hospital ensino do sul do país. Acta Scientiarum. Health Sciences, Maringá, 34(1), 9-15. https://doi.org/10.4025/actascihealthsci.v34i1.8946

Telo, S. V. \& Witt, R. R. (2018). Saúde sexual e reprodutiva: competências da equipe na Atenção Primária à Saúde. Ciência \& Saúde Coletiva, 23(11), 3481-3490. https://doi.org/10.1590/1413-812320182311.20962016

Vieira, P. M. \& Matsukura, T. S. (2017). Modelos de educação sexual na escola: concepções e práticas de professores do ensino fundamental da rede pública. Revista Brasileira de Educação, 22(69), 453-464. https://doi.org/10.1590/S1413-24782017226923

\section{CONFLITOS DE INTERESSES}

Os autores declaram a inexistência de conflitos de interesses, tanto na execução das ações do projeto de pesquisa como na escrita deste manuscrito.

\section{FINANCIAMENTO}

Coordenação de Aperfeiçoamento de Pessoal de Nível Superior - CAPES (Bolsa de Mestrado).

Conselho Nacional de Desenvolvimento Científico e Tecnológico - CNPq (Bolsa Pós-Doutorado)

\section{SOBRE OS AUTORES}

Catiele dos Santos é Doutoranda em Psicologia pelo Programa de Pós-Graduação em Psicologia da Universidade Federal de Santa Maria (UFSM).

e-mail: cati92sw@gmail.com

(2) https://orcid.org/0000-0002-1900-0735

Adriane Roso é Professora Associada no Departamento de Psicologia da Universidade Federal de Santa Maria - UFSM (Graduação e Pós-graduação), Doutora em Psicologia pela Pontifícia Universidade Católica do Rio Grande do Sul - PUCRS (2005), Pós-Doutora pela Harvard University (2019).

e-mail: adriane.roso@ufsm.br.

(2) https://orcid.org/0000-0001-7471-133X

Flavi Ferreira Lisbôa Filho é Professor Associado no Departamento de Ciências da Comunicação da Universidade Federal de Santa Maria - UFSM (POSCOM/UFSM). Pró-Reitor de Extensão da UFSM. Doutor em Ciências da Comunicação pela Universidade do Vale do Rio dos Sinos (2009).

e-mail: flavilisboa@gmail.com

https://orcid.org/0000-0003-4307-9401 